Can the impact of body dissatisfaction on disordered eating be weakened by one's decentering abilities?

Lara Palmeira, Inês A. Trindade, \& Cláudia Ferreira 2014

Eating Behaviors 15(3): 392-396 doi: 10.1016/j.eatbeh.2014.04.012 


\title{
Can the impact of body dissatisfaction on disordered eating be weakened by one's decentering abilities?
}

\author{
Lara Palmeira, Inês A. Trindade, \& Cláudia Ferreira
}

\begin{abstract}
Decentering has been defined as the ability to deal with thoughts and emotions as subjective and ephemeral inner events. Since it implies a non-judging and present focused attitude towards thoughts and emotions, decentering has been considered as an important protective process against psychopathology, as it has been empirically shown to decrease depressive relapse rates. Nevertheless, its role in eating disordered attitudes and behaviours has not been fully uncovered.

Therefore, the aim of the present study is to explore the moderator effect of decentering on the relationship between eating psychopathology and one of its main risk factors, body image dissatisfaction.

The sample comprised 279 female students, aged between 14 and 21 years-old. Results revealed that decentering abilities were negatively linked to body image dissatisfaction and to the global score of eating psychopathology. Through a path analysis, the buffer effect of decentering was confirmed.

The findings suggest that the ability to take a non-judgmental and accepting stance towards internal experiences diminishes the impact of one's body dissatisfaction on disordered eating attitudes and behaviours. This study seems especially pertinent since it uncovers a mechanism to lessen the pervasive impact of body image dissatisfaction, which is highly prevalent in women from Western societies.
\end{abstract}

Key-words: decentering; eating psychopathology; body image dissatisfaction; emotional regulation processes; moderator effect. 


\section{Introduction}

Decentering has been pointed as an important protective mechanism in regard of psychopathological conditions and a core change process in therapy (Hayes, Strosahl, \& Wilson, 1999; Sauer \& Baer, 2010; Segal, Williams, \& Teasdale, 2002; Teasdale et al., 2002). This process is defined as the ability to deal with one's inner experiences (thoughts and emotions) as subjective and ephemeral inner events. That is, being contrary to a self-focused form of attention, decentering allows the detached observation of one's thoughts and feelings, recognizing them as products of the mind (versus reflections of the self or reality) that do not require particular responses (Fresco, Moore, et al., 2007).

The construct of decentering, first introduced by Safran and Segal (1990), has been the focus of particular interest from the classical cognitive-behavioural therapy to the more recent third wave models (e.g., Mindfulness and Acceptance and Commitment Therapy; Fresco, Moore, et al., 2007) due to its capacity to produce long-term treatment effects (Ingram \& Hollow, 1986). Throughout history, crucial to the conceptualization of decentering is the ability to take a present-focused, nonjudging and accepting attitude towards thoughts and feelings (Fresco, Segal, Buis, \& Kennedy, 2007). In fact, decentering seems to imply a mindful stance, since it translates the capacity to observe the temporal stream of internal experiences as they occur in the mind (Bishop et al., 2004; Safran \& Segal, 1990).

Furthermore, decentering describes a fundamental shift in perspective that allows one to be less attached to unwanted thoughts and feelings (e.g., Teasdale, Segal, Williams, 1995; Teasdale et al., 2002; Wells, 2002). As it reduces automatic cognitive patterns, including rumination and obsession, this shift may have multiple psychological and behavioural advantages (Teasdale et al., 2002). Moreover, it may potentiate a nonreaction to negative experiences and the ability to be self-compassionate (Segal et al., 2006). In this sense, decentering may be conceptualized as a functional emotion regulation process to cope with unwanted internal events, allowing the adoption of adaptive choices before aversive events. In fact, theoretical and empirical evidence have revealed that the ability to take a decentered perspective on internal experiences holds positive correlations to well-being and mental health (Fresco, Moore, et al., 2007). More specifically, it has been linked with protection against depressive symptoms and relapse (Ingram \& Hollon, 1986; Teasdale, 2002). 
To date, however, there has been little work that clarifies the importance of decentering in eating psychopathology. Nonetheless, recent research has recognised that emotion regulation difficulties assume a crucial role to the development of disordered eating attitudes and behaviours (Ferreira, Trindade, Duarte, \& Pinto-Gouveia, 2013; Lavender, Jardin, \& Anderson, 2009; Merwin et al., 2011; Trindade \& Ferreira, 2013; Whiteside et al., 2007). These difficulties include experiential avoidance, the incapability of being in the present moment and the tendency to take a judgmental stance about thoughts and feelings (Lavender et al., 2009). Indeed, disordered eating behaviours (such as binge eating, purging and excessive exercise) may be seen as strategies to avoid or control unwanted internal experiences related to one's body image (e.g., body image dissatisfaction; Merwin et al., 2011; Trindade \& Ferreira, 2013).

Body image dissatisfaction is, indeed, an acknowledged risk factor for eating psychopathology (Stice, Marti, \& Durant, 2011) and has also gathered attention of several studies within the third wave of cognitive-behavioural therapy. In fact, the negative evaluation of one's body weight and shape has been considered as a source of pervasive psychological distress and is associated with disordered eating attitudes and behaviours even among women without eating psychopathology (e.g., Lewis \& Cachelin, 2001; Niemeir, 2004). Furthermore, recent data suggests that the prevalence of body image dissatisfaction and associated disordered eating behaviours may be reduced via an increase in psychological flexibility when dealing with unwanted weight-related thoughts and feelings (Lillis, Hayes, Bunting, \& Masuda, 2009).

Several therapies have therefore included acceptance- and awareness-based modules in the treatment of the body image and eating disorders' field (e.g., Acceptance and Commitment Therapy, Hayes et al., 1999; Mindfulness-based eating awareness training, Kristeller \& Hallett, 1999). These forms of therapy encourage a nonjudgemental and nonresponsive observation of body-related thoughts, images and fears, instead of responding to those events with maladaptive behaviours (Heffner, Sperry, Eifert, \& Detweiler, 2002; Safer, Telch, \& Agras, 2001; Telch, Agras, \& Linehan, 2000). However, although these therapies are definitely promising in eating psychopathology (e.g., Baer, Fisher, \& Huss, 2006; Merwin, \& Wilson, 2009), little research has been performed concerning the association between decentering and such disorders. Before this lack in literature, the current study aims to clarify whether the ability to take a decentered perspective regarding unwanted inner experiences has a 
buffer effect on the impact of dissatisfaction with body weight and shape on disordered eating difficulties.

\section{Methods}

\subsection{Participants}

Two hundred and seventy nine female students, ranged from 14 to 21 years of age, enrolled in the study. The participants presented an average age of 17.88 years old $(S D=1.95)$ and a mean of 11.63 years of education $(S D=1.86)$.

\subsection{Measures}

Demographic Data. Participants were asked to report their age, completed educational level, and current height and weight. $\mathrm{BMI}\left(\mathrm{Wt} / \mathrm{Ht}^{2}\right)$ was then calculated.

Experiences Questionnaire (EQ; Fresco, Moore, et al., 2007; Pinto-Gouveia, Gregório, Duarte, \& Simões, 2012). The EQ comprises 11 items designed to assess decentering in daily experiences (e.g., "I notice all sorts of little things and details in the world around me"; "I think over and over again about what others have said to me"). Items are scored on a 5-point Likert scale (1 - Never; 5 - Always), according to their frequency. Higher scores imply greater ability to view one's thoughts and feelings as temporary and separated from the self. The EQ revealed good internal consistency values, having Cronbach's alpha values of .83 in the original version and .81 in the Portuguese validation study.

Figure Rating Scale (FRS; Thompson \& Altabe, 1991; Ferreira, 2003). The FRS is a well-known measure that presents nine silhouettes, ranging from very thin (1) to very large (9). The participant is asked to choose two figures: one that best translates her current body size and one that reflects her ideal body shape; the divergence between these two silhouettes indicates the level of body image dissatisfaction (BD). According to Thompson and Altabe (1991), the scale holds good temporal, convergent and divergent validities.

Eating Disorder Examination Questionnaire (EDE-Q; Fairburn \& Beglin, 1994; Machado, 2007). The EDE-Q is a 36 item self-report questionnaire that was adapted from the Eating Disorder Examination interview. This scale evaluates the participants' psychopathological eating attitudes and behaviours over a 28 day period in a scoring system of 0-6 (0 no days; 6 - everyday).The EDE-Q includes 4 subscales (restraint, 
eating concern, shape concern and weight concern) and also a global score of eating psychopathology. In the present study only the global score from the EDE-Q was used as we were interested in measuring the severity of eating psychopathological symptoms. In accordance to Fairburn (2008), the EDE-Q holds good reliability values and may be used to discriminate eating psychopathology cases.

The study variables' Cronbach's alphas are presented in Table 1.

\subsection{Procedures}

The study was granted ethical approval from the ethics committees of the educational institutions enrolled in the research. Participants were female students recruited from several middle and high schools and also from the University of Coimbra. All the female students from the schools enrolled in the study were invited to participate. Participants (and their parents, if they were minor) were fully informed about the aim of the study and the confidential nature of the data before completing several self-report measures. The majority of the invited students accepted to participate in the study and signed the consent form. Students who did not participate were given a task by the teacher. The questionnaires were completed during class (in approximately 30 minutes), in the presence of the teacher and one of the researchers that provided further explanations when needed, in order to ensure the correct fulfilment of the measures.

\subsubsection{Data analysis}

Data analyses were performed using IBM SPSS Statistics 20 (IBM Corp, 2011) and Path analyses were examined using the software AMOS.

Descriptive statistics (means and standard deviations) were used to explore the sample's characteristics in the study variables.

Pearson correlation coefficients were conducted to explore the association between decentering (EQ), body dissatisfaction (BD), BMI and the severity of eating disorders symptomatology assessed by EDE-Q (Cohen, Cohen, West, \& Aiken, 2003).

In order to test the moderator effect of decentering in the relationship between BD and eating psychopathology's severity, a Path analysis was performed to estimate the presumed relations of the proposed theoretical model (Figure 1). The moderator model presents three causal paths to the dependent variable (EDE-Q): (a) the impact of body dissatisfaction; (b) the impact of decentering; (c) the interaction of these two 
variables. The moderator hypothesis is corroborated if the interaction (path c) is significant. The Maximum Likelihood method was used to estimate all model path coefficients. To reduce the error related to multicollinearity, a standardized procedure was used, centering the values of the predictor and moderator (namely, BD and EQ) and then it was obtained the interaction variable through the product of the created variables (Aiken \& West, 1991).

To confirm the invariance of the structure of this model throughout our sample's age range a multi-group analysis was conducted. Two groups were built according to the participants' age (Group 1: age between 14 to 17 and group 2: age between 18 to 21 years old). To determine whether any statistically significant differences existed between the two groups, the unconstrained and constrained models were compared. The statistical significance of the difference between the two models was verified by the chisquare difference test.

Finally, to better understand the relationship between BD and eating psychopathology's severity (EDE-Q) towards different levels of decentering, a graphic was plotted. As recommended by Cohen and colleagues (2003) and since the moderator variable has no theoretical cut-points, we considered the following cut-point values: $M-$ $S D ; M$ and $M+S D$, to create three curves of different levels of decentering. Additionally, a simple slope analysis was performed to confirm if the effect of BD on EDE-Q was statistically significant at high, medium and low values of decentering (Jose, 2013).

\section{Results}

\subsection{Preliminary Data Analyses}

The Skewness (sk) and Kurtosis (ku) statistics were conducted to test the suitability of the current data. Results showed that the distribution of the data was normal (sk $<|3|$ and $\mathrm{Ku}<|8-10|$; Kline, 2005). No multivariate outliers were found through Mahalanobis distance statistic. Additionally, multicollinearity amongst the variables was assessed through Variance Inflaction Factor (VIF) values $(<5)$, which corroborated the adequacy of the data. 


\subsection{Descriptives}

Table 1 shows the mean and standard deviation for each of the study variables.

Table 1

Means (M), Standard Deviations (SD), Cronbach's alphas and Intercorrelation scores on self-report measures $(N=345)$

\begin{tabular}{cccccccr}
\hline Measures & $M$ & $S D$ & A & EQ & BMI & BD & EDE-Q \\
\hline EQ & 33.68 & 6.07 & .85 & - & & \\
BMI & 21.16 & 2.72 & - & $-.15^{*}$ & - & \\
BD & .60 & .92 & - & $-.34^{* * *}$ & $.54 * * *$ & - \\
EDE-Q & 1.51 & 1.36 & .96 & $-.51^{* * *}$ & $.38^{* * *}$ & $.59 * * *$ \\
\end{tabular}

\subsection{Correlations}

Pearson product-moment correlations showed that EQ was negatively correlated to BD, EDE-Q and, albeit weakly, to BMI.

BMI was found to correlate positively and moderately with higher levels of body dissatisfaction (BD) and eating psychopathology (EDE-Q). These last two mentioned variables held, as expected, a positive and moderate correlation with each other.

\subsection{Moderation analysis}

The aim of the path analysis was to test whether decentering moderated the effect of body image dissatisfaction on eating psychopathology severity.

In this model, all path coefficients were statistically significant and explained $47 \%$ of eating psychopathology. BD presented a direct positive effect $\left(b=.670 ; \mathrm{SE}_{\mathrm{b}}=\right.$ $.069 ; \mathrm{Z}=9.709 ; \mathrm{p}<.001 ; \beta=.453)$ and $\mathrm{EQ}$ revealed a direct negative effect $(b=-.078$; $\left.\mathrm{SE}_{\mathrm{b}}=.010 ; \mathrm{Z}=-7.499 ; \mathrm{p}<.001 ; \beta=-.348\right)$ towards EDE-Q. The interaction effect between the two variables was $b=-.026\left(\mathrm{SE}_{\mathrm{b}}=.010 ; \mathrm{Z}=-2.638 ; \mathrm{p}=.008 ; \beta=-.116\right)$. All analysed effects are highly significant and suggest the existence of a moderator 
effect of decentering on the association between body image dissatisfaction and eating psychopathology symptoms.

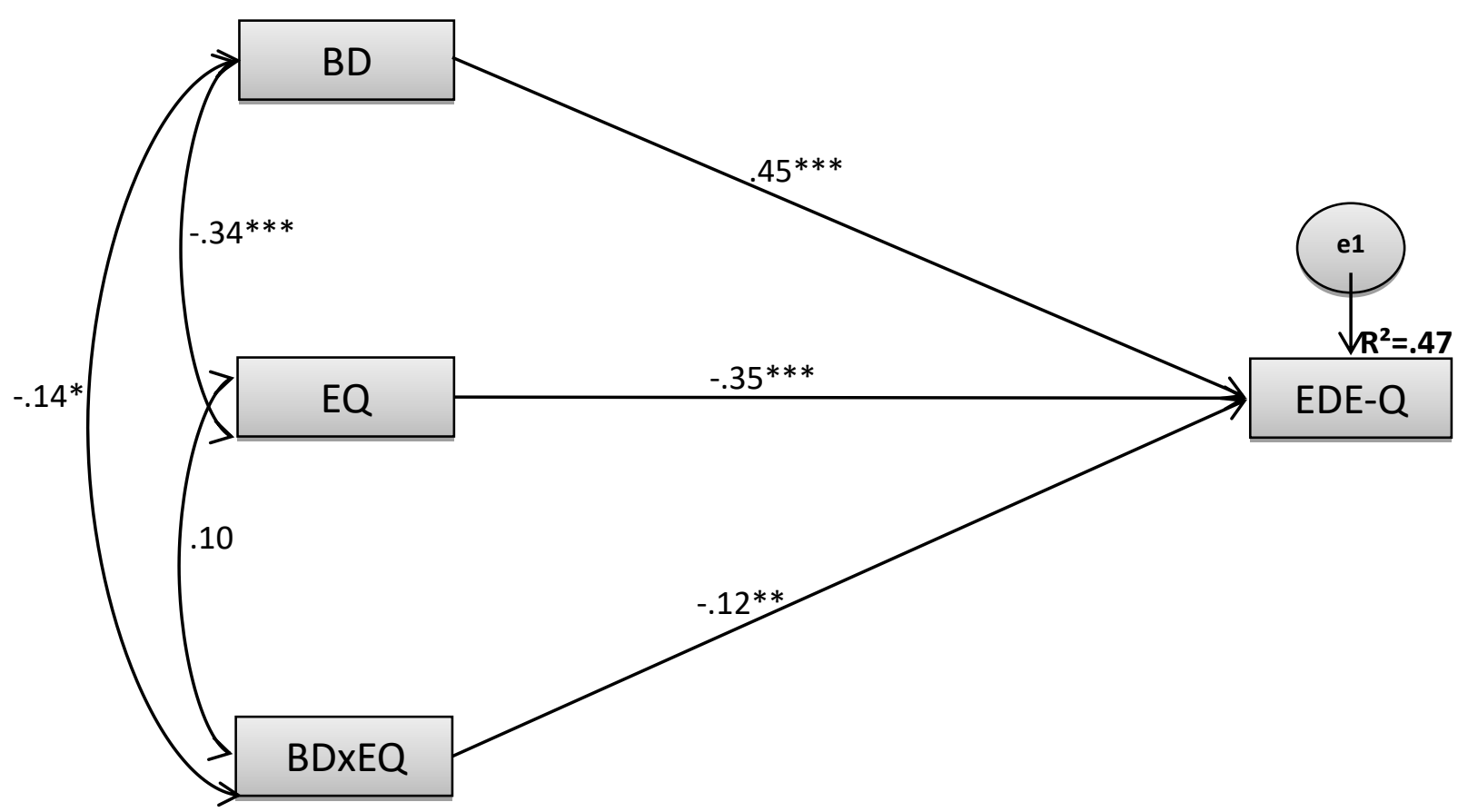

Figure_1. Final Path Model

Note. ${ }^{*} p<.05 ;{ }^{* *} p<.01 ;{ }^{* * *} p<.001$. Standardized path coefficients among variables are presented.

Given the fact that the sample comprised female adolescents and young adults and that age can explain differences in cognitive abilities and eating disorder symptoms a multi-group analysis was conducted. This analysis tested the invariance of the model across two groups, according to participants' age. The comparison between the unconstrained and constrained model revealed a non-significant chi-square difference $\left(\Delta \chi^{2}{ }_{(3)}=2.499 ; \mathrm{p}=.476\right)$. Furthermore, results show that the quality of the model fit of the constrained model was not significantly different than the one from the unconstrained model $\left(\Delta \chi_{(4)}^{2}=7.558 ; \mathrm{p}=.109\right)$. These results indicate that it is appropriated to assume that the tested model is equivalent for both age groups.

With the purpose of better understanding the relationship between BD (independent variable) and EDE-Q (dependent variable) towards different levels of EQ 
(moderator variable), a graphic was computed considering low, medium and high levels of decentering.

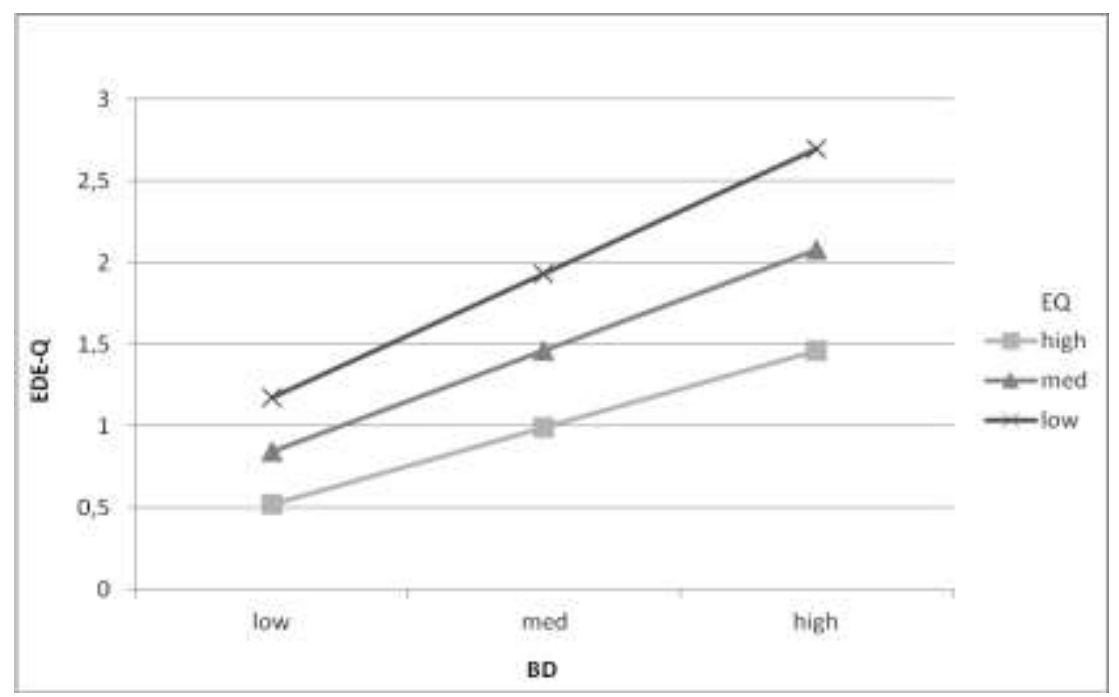

Graphic 1. Graphic for the relation between body image dissatisfaction (BD) and eating psychopathology (EDE-Q) with different levels of decentering (EQ).

The graphic revealed that, for the same level of $\mathrm{BD}$, the female students who scored higher in EQ presented lower EDE-Q values. In other words, young females who presented higher decentering abilities, showed inferior levels of eating psychopathology in comparison to those who have medium and lower values of EQ. In fact, this graphic representation allows us to observe the buffer effect of decentering against the impact of body image dissatisfaction on the severity of eating psychopathology. It is also interesting to point that female students who showed higher BD and higher EQ values revealed a similar level of EDE-Q when compared to participants with lower BD but with a lack of ability to decenter from inner events. The simple slope analysis confirmed that the effect of BD on EDE-Q was statistically significant for all levels of decentering $\left(\mathrm{t}_{\text {high_EQ }}(275)=2.58, \mathrm{p}=.010 ; \mathrm{t}_{\text {medium_EQ }}(275)=6.22, \mathrm{p}<.001 ; \mathrm{t}_{\text {low_EQ }}(275)=13.28, \mathrm{p}<\right.$ $.001)$.

\section{Discussion}

This paper explores the role of the ability to take a decentered stance (concerning unwanted thoughts and emotions) in the relationship between dissatisfaction with body weight and shape and eating psychopathology severity. More 
specifically, the current study tests the moderator effect of decentering on such relationship in a sample of female students.

The results from the correlation analyses revealed that the ability to take a decentered perspective regarding one's inner experiences is inversely associated with higher levels of body image dissatisfaction and disordered eating. These findings are in line with previous research which suggested that a lack of decentering abilities is associated with several maladaptive psychological and behavioural features (Fresco, Moore, et al., 2007; Teasdale et al., 2002). These results also extend the existing literature, by revealing the link between decentering towards body image dissatisfaction and eating psychopathology.

To test the hypothesis that decentering may moderate the effect of body image dissatisfaction on disordered eating attitudes and behaviours a path analysis was conducted. Overall, the tested moderation model accounted for $47 \%$ of eating psychopathology's variance. Results also showed that body image dissatisfaction presented a direct positive effect, while decentering revealed a direct negative effect, towards a global score of eating psychopathology. Additionally, the moderator effect of decentering was verified since the interaction between body image dissatisfaction and decentering revealed a significant effect upon the levels of eating psychopathology severity. The same is to say that on young females who have the ability to decenter themselves from their inner experiences, the impact of body image dissatisfaction on disordered eating attitudes and behaviours is diminished. The plotted graphic representation evidenced such moderator effect. For the same level of body image dissatisfaction, the participants that reported decreased abilities of decentering revealed an increased level of overall eating psychopathology symptoms, comparatively to those who revealed higher tendency to decenter from their thoughts and emotions. Interestingly, it was also found that the female students who have greater body image dissatisfaction and higher capabilities to decenter showed approximately the same (although slightly higher) level of eating psychopathology than those who presented lower levels of body image dissatisfaction but fewer abilities to decenter.

Taken together, these results seem to suggest that young females who are able to observe their inner experiences as transient and subjective events may reveal less tendencies to engage in maladaptive eating behaviours (e.g., restraint, purging, binge eating), even in face of perceptions of their body flaws and imperfections. In other words, the ability to take a decentered perspective seems to weaken the impact of 
negative weight and shape perceptions on the engagement on disordered eating attitudes and behaviours.

The moderator effect of decentering is an interesting finding that extends previous research regarding the role of emotional regulation processes in eating psychopathology, and may have relevant clinical implications. Although the newer mindfulness- and acceptance-based therapies adapted to the treatment of eating disorders are promising, there was still little empirical support on the role of the different emotional regulation processes involved. Specifically regarding decentering, and as far as we know, this is the first study that suggests its moderator effect against disordered eating behaviours. Indeed, the present study seems to corroborate the importance of developing more adaptive strategies, such as decentering, in intervention programs in this field.

Nevertheless, these results should be interpreted considering some methodological limitations. Firstly, the cross-sectional nature of the data limits any causal inferences. Indeed, prospective studies are necessary to corroborate the nature and direction of the tested model. Secondly, we used a non-clinical student sample and, in that sense, future research should replicate these findings in eating disorders samples. Still, we used this specific sample because eating disordered attitudes and behaviours are a significant problem for student populations (Luce, Crowther, \& Pole, 2008; O'Dea \& Abraham, 2002). Finally, we relied on self-report measures which may constraint the obtained data.

To sum up, we believe our study helps to uncover the role of decentering from one's thoughts and feelings against the pervasive effect of body image dissatisfaction on body and eating difficulties. This is particularly relevant since body image dissatisfaction is almost "normative" on Western society women. Therefore, our results point out that the ability to take a decentered perspective may be highly important to reduce the risk of developing disordered eating behaviours. 


\section{References}

Aiken, L. S., \& West, S. G. (1991). Multiple regression: Testing and interpreting interactions. Newbury Park: Sage.

Baer, R. A., Fischer, S., \& Huss, D. B. (2006). Mindfulness and acceptance in the treatment of disordered eating. Journal of Rational-Emotive \& CognitiveBehavior Therapy, 23(4) 281-3011. doi: 10.1007/s10942-005-0015-9

Bishop, S. R., Lau, M., Shapiro, S. L., Carlson L., Anderson, N. D., Carmody, J., ... Devins, G. (2004). Mindfulness: A proposed operational definition. Clinical Psychology: Science and Practice, 11, 230-241.

Brown. K. W., \& Ryan, R. M. (2003). The Benefits of Being Present: Mindfulness and Its Role in Psychological Well-Being. Journal of Personality and Social Psychology, 84, 822-848.

Carlson, L.E. \& Brown, K.W. (2005). Validation of the Mindful Attention Awareness Scale in a cancer population. Journal of Psychosomatic Research, 58, 29-33.

Cohen, J., Cohen, P. West, S. \& Aiken, L. (2003). Applied multiple regression/correlation analysis for the behavioural sciences (3th ed.). New Jersey: Lawrence Erlbaum Associates.

Fairburn, C. G. (2008). Cognitive behavior therapy and eating disorders. New York: The Guilford Press.

Fairburn, C. G., \& Beglin, S. J. (1994). Assessment of eating disorders: Interview or self-report questionnaire? International Journal of Eating Disorders, 16, 363370.

Ferreira, C. (2003). Anorexia Nervosa: A expressão visível do invisível. Contributos para a avaliação de atitudes e comportamentos em relação ao peso e à imagem corporal [Anorexia Nervosa: The visible expression of the invisible. Contributions for the assessment of attitudes and behaviors in relation to weight and body image]. (Unpublished master's thesis). University of Coimbra, Coimbra.

Ferreira, C., Trindade, I. A., Duarte, C., \& Pinto-Gouveia, J. (2013). Getting entangled with body image: Development and validation of a new measure. Manuscript submitted for publication.

Fresco, D. M., Moore, M. T., van Dulmen, M. H. M., Segal, Z. V., Ma, S. H., Teasdale, J. D., \& Williams, M. (2007). Initial psychometric properties of the experiences 
questionnaire: Validation of a self-report measure of decentering. Behavior Therapy, 38(3), 234-246.

Fresco, D. M., Segal, Z. V., Buis, T., \& Kennedy, S. (2007). Relationship of post treatment decentering and cognitive reactivity following an emotion evocation challenge to relapse of major depressive disorder. Journal of Consulting and Clinical Psychology, 75, 447-455.

Hayes, S. C., Strosahl, K. D., \& Wilson, K. G. (1999). Acceptance and Commitment Therapy: An experiential approach to behavior change. New York: Guilford Press.

Heffner, M., Sperry, J., Eifert, G. H., \& Detweiler, M. (2002). Acceptance and commitment therapy in the treatment of an adolescent female with anorexia nervosa: A case example. Cognitive and Behavioral Practice, 9, 232-236.

Ingram, R. E., \& Hollon, S. D. (1986). Cognitive therapy for depression from an information processing perspective. In R. E. Ingram (Ed.), Information processing approaches to clinical psychology. (pp. 259-281). San Diego, CA: Academic Press.

Jose, P.E. (2013). ModGraph-I: A programme to compute cell means for the graphical display of moderational analyses: The internet version, Version 3.0. Victoria University of Wellington, Wellington, New Zealand. Retrieved [October, 2013] from http://pavlov.psyc.vuw.ac.nz/paul-jose/modgraph/

Kline, R.B. (2005). Principles and Practice of Structural Equation Modeling (2nd edition). New York: The Guilford Press.

Kristeller, J. L., \& Hallett, C. B. (1999). An exploratory study of a meditation-based intervention for binge eating disorder. Journal of Health Psychology, 4(3),357363.

Lavender, J. M., Jardin, B. F., \& Anderson, D. A. (2009). Bulimic symptoms in college men and women: Contributions of mindfulness and thought suppression. Eating Behaviors, 10, 228-231.

Lewis, D. M., \& Cachelin, F. M. (2001). Body image, body dissatisfaction, and eating attitudes in mid-life and elderly women. Eating Disorders: The Journal of Treatment and Prevention, 9, 29-39.

Lillis, J., Hayes, S. C., Bunting, K., \& Masuda, A. (2009). Teaching acceptance and mindfulness to improve the lives of the obese: A preliminary test of a theoretical model. Annals of Behavioral Medicine, 37, 58-69 
Luce, K.H., Crowther, J.H., \& Pole, M. (2008). Eating Disorder Examination Questionnaire (EDE-Q): Norms for Undergraduate Women. International Journal of Eating Disorders, 41, 273-276.

Machado, P. P., (2007). Versão Portuguesa do EDE-Q, 5aedição [Portuguese Version of $E D E-Q, 5^{\text {th }}$ edition]. Unpublished manuscript. University of Minho.

MacKinnon, D. P. (2008). Introduction to Statistical Mediation Analysis. Mahwah, NJ: Erlbaum.

Merwin, R. M., \& Wilson, K. G. (2009). Understanding and treating eating disorders: An ACT perspective. In J. T. Blackledge, J. Ciarrochi, \& F. P. Deane (Eds.), Acceptance and Commitment Therapy: Contemporary Theory, Research, and Practice (pp. 87-117). Australia: Australian Academic Press.

Merwin, R. M., Timko, C. A., Moskovich, A. A., Ingle, K. K., Bulik, C. M., \& Zucker, N. L. (2011). Psychological Inflexibility and Symptom Expression in Anorexia Nervosa. Eating Disorders, 19, 62-82.

Niemeir, H.M. (2004). Clinical implications of disordered eating attitudes and behaviors in college women. Dissertation Abstracts International: Section B - The Physical Sciences and Engineering , 65, 1035

O'Dea J., \& Abraham S. F. (2002). Eating and exercise disorders in young college men. Journal of American College Health, 5, 273-278.

Pinto-Gouveia, Gregório, S., Duarte, C., \& Simões, L. (2012). Decentering: Psychometric properties of the Portuguese version of the experiences questionnaire (EQ). In R., Quevedo-Blasco \& V., Quevedo-Blasco (Eds.), Avances en psicología clínica (pp. 445-449). Santander: Asociación Española de Psicología Conductual (AEPC). URL: http://www.ispcs.es/xcongreso/portugues/livroresumos.html

Safer, D. L., Telch, C. F., \& Agras, W. S. (2001). Dialectical behavior therapy for bulimia nervosa. American Journal of Psychiatry, 158, 632-634.

Safran, J. D., \& Segal, Z. V. (1990). Interpersonal process in cognitive therapy. Lanham, MD: Jason Aronson.

Sauer, S., \& Baer, R. A. (2010). Mindfulness and decentering as mechanisms of change in mindfulness- and acceptance-based interventions. In R. A. Baer (Ed.), Assessing mindfulness and acceptance processes in clients: Illuminating the

Schumacker, R. E., \& Lomax, R. G. (2004). A beginner's guide to structural equation modeling (2nd edition). Mahwah, NJ: Lawrence Erlbaum Associates. 
Segal, Z. V., Kennedy, S., Gemar, M., Hood, K., Pedersen, R., \& Buis, T. (2006). Cognitive reactivity to sad mood provocation and the prediction of depressive relapse. Archives of General Psychiatry, 63, 749-755.

Segal, Z. V., Williams, J. M. G., \& Teasdale, J. D. (2002). Mindfulness-based cognitive therapy for depression: A new approach to preventing relapse. New York, NY: Guilford Press.

Stice, E., Marti., N., \& Durant, S. (2011). Risk factors for onset of eating disorders: Evidence of multiple risk pathways from an 8-year prospective study. Behaviour Research and Therapy, 49(10), 622-627. doi:10.1016/j.brat.2011.06.009

Teasdale, J. D., Moore, R. G., Hayhurst, H., Pope, M., Williams, S., \& Segal, Z. V. (2002). Metacognitive awareness and prevention of relapse in depression: Empirical evidence. Journal of Consulting and Clinical Psychology, 70(2), 275287.

Teasdale, J. D., Segal, Z., \& Williams, J. M. G. (1995). How does cognitive therapy prevent depressive relapse and why should attentional control (mindfulness) training help? Behaviour Research and Therapy, 33(1), 25-39.

Telch, C. F., Agras, W. S., \& Linehan, M. M. (2000). Group dialectical behavior therapy for binge-eating disorder: A preliminary uncontrolled trial. Behavior Therapy, 31, 569-582. theory and practice of change (pp. 25-50). New Harbinger.

Thompson, J. K., \& Altabe, M. N. (1991). Psychometric qualities of the figure rating scale. International Journal of Eating Disorders, 10, 615-619. doi: 10.1002/1098- 108X(199109) 10:5.

Trindade, I. A., \& Ferreira, C. (2013). The impact of body image-related cognitive fusion on eating psychopathology. Manuscript submitted for publication.

Wells, A. (2002). GAD, metacognition, and mindfulness: An information processing analysis. Clinical Psychology: Science and Practice, 9(1), 95-100.

Whiteside, U., Chen, E., Neighbors, C., Hunter, D., Lo, T., \& Larimer, M. (2007). Difficulties regulating emotions: Do binge eaters have fewer strategies to modulate and tolerate negative affect? Eating Behaviors, 8(2), 162-169. doi: 10.1016/j.eatbeh.2006.04.001 